\title{
O ENSINO DE CIÊNCIAS NA ESCOLA PÚBLICA SERGIPANA: O OLHAR DE ALUNOS DO ENSINO MÉDIO DO COLÉGIO FRANCISCO ROSA
}

\section{ARTIGO ORIGINAL}

SILVA, Roberto Carlos da ${ }^{1}$

SILVA, Roberto Carlos da. O ensino de ciências na Escola Pública sergipana: 0 olhar de alunos do Ensino Médio do Colégio Francisco Rosa. Revista Científica Multidisciplinar Núcleo do Conhecimento. Ano 05, Ed. 09, Vol. 09, pp. 56-81. Setembro de 2020. ISSN: 2448-0959, Link de acesso: https://www.nucleodoconhecimento.com.br/educacao/ensino-de-ciencias

\section{RESUMO}

O presente trabalho objetivou conhecer as perspectivas dos alunos do ensino médio do Colégio Estadual Francisco Rosa Santos, na cidade de Aracaju, capital do Estado de Sergipe, sobre o ensino de ciências biológicas na escola pública sergipana. Para tanto, foi realizada uma abordagem do tipo quanti-qualitativa, com amostragem representativa, operacionalizada através de questionários semiestruturados. As contribuições da pesquisa proporcionaram ao pesquisador conhecer, de forma mais vivencial, por meio da amostragem, como se encontra a realidade no ensino de ciências biológicas nesta realidade, bem como as metodologias e recursos utilizados. Os dados revelaram que o método tradicional de ensino ainda está muito presente e operante. Daí, apresentou-se alternativas metodológicas a este modelo como a utilização de projetos de ensino que utilize recursos tecnológicos midiáticos, bem

1 Mestre em Educação (2004) pela Universidade Federal de Sergipe - UFS; Especialista em Novas Tecnologias e Desenvolvimento Regional ((2000) pela UFS; Licenciado em Pedagogia (1990) pela UFS; e Licenciado em Matemática (2014) pela Faculdade de Ciências da Bahia - FACIBA; Licenciado em Ciências Biológicas (2019) pelas Faculdades Integradas de Ariquemes - FIAR. 
como a realização de práticas experimentais em laboratórios e as pesquisas de campo como forma de dinamizar as aulas, torná-las mais atrativas, com participação ativa dos alunos e melhoria da aprendizagem.

Palavras-chave: Metodologias de ensino, Ciências Biológicas, Escola pública.

\section{INTRODUÇÃO}

No transcorrer do século XXI nos deparamos com uma sociedade midiática, denominada sociedade da informação, com imensas possibilidades de transmissão de dados, conhecimentos e informações, volátil e em constante transformações, bastante impulsionada pelas novas tecnologias da comunicação e da informação, as TICs, que dimensiona tanto o comportamento das pessoas como as mudanças e transformações sociais, haja vista, as inúmeras possibilidades que estas proporcionam.

Neste novo paradigma social encontra-se a escola enquanto organização social que trabalha com a informação - a matéria prima do processo de ensino e aprendizagem - que neste novo contexto encontra-se mais disponibilizadas em outros meios, os midiáticos, para além do livro didático.

Assim, muitos destes aspectos relacionados a situação da escola nos dias atuais tem sido intensamente discutido na seara acadêmica, como também, nas instituições educacionais (secretarias de educação, escolas, associações de classes, sindicatos, etc.), em função da iminente crise que circunda o meio: são professores estressados e sem ânimo e com elevada carga de cansaço que afeta de forma significativa a sua vida, saúde e comportamento, consequentemente refletindo na sua prática pedagógica. Por outro lado, os alunos não conseguem aprender de forma significativa, encontram-se desmotivados e desinteressados nos conteúdos propostos das matrizes curriculares. Desta forma, a escola torna-se cada vez mais uma rotina frustrante, desestimulante, sem provocar o ânimo de seus protagonistas. 
Daí, indaga-se: Por que a escola está tomando esta projeção? O que tem levado os alunos a não gostar da sala de aula? Seria o modo como tem sido conduzido o ensino que frustra e desmotiva os alunos? Por que os egressos do sistema de ensino não têm apresentado conhecimentos e habilidades necessárias para o desenvolvimento da vida social e do mundo do trabalho? Por que as aulas de ciências biológicas não são interessantes?

No primeiro momento, supõe-se que são inúmeras as questões que precisam ser investigadas. É possível que existam inúmeros fatores que favoreceram ao surgimento de tais anomalias no ambiente escolar, dentre as quais pode se pode se enumerar desde a falta de investimentos na educação, passando pela desvalorização do professor, a necessidade de formação continuada, que poderá refletir nas metodologias defasadas.

Neste trabalho, defende-se que a maneira pela qual as aulas têm sido conduzidas pode ser um dos fatores de desgaste da imagem da escola. Para tentar auxiliar no entendimento dessa situação, propõe-se analisar o modo como a maioria das escolas propõem suas práticas pedagógicas no ensino de ciências biológicas, como também, indicar alternativas a esta situação.

Primeiramente, discute-se o modelo tradicional de aulas expositivas no ensino de ciências biológicas. Em seguida, é sugerido metodologias alternativas para auxiliar o desenvolvimento do ensino de ciências biológicas, tais como a intensificação do uso de recursos midiáticos como suporte tecnológico para as atividades pedagógicas, bem como a realização de aulas experimentais realizadas com materiais concretos em laboratórios, com intuito de que se possa romper com a situação de estagnação neste segmento do ensino.

Os recursos estratégicos analisados: o uso intensivo de recursos midiáticos e práticas experimentais, são alternativas que dinamizam o dia a dia das aulas de ciências, sempre na perspectiva de ter o professor enquanto coordenador do processo de aprendizagem que investe no protagonismo dos alunos na construção do seu conhecimento. 
Nesta perspectiva, este trabalho tem o intuito de verificar, sob a ótica dos discentes do ensino médio da escola pública de Aracaju, qual a sua percepção do ensino e aprendizagem do componente curricular Ciências Biológicas e, a partir destas respostas, propor alternativas para dinamizar o ensino nesta área, tornando-o mais atraente para o aluno, e assim promovendo mais qualidade na aprendizagem.

Para a delimitação desta proposta, inicialmente aborda-se o ensino de ciências biológicas no modelo tradicional, em virtude de ser uma prática bastante usual na escola nos dias atuais. A partir destes esclarecimentos, apresenta-se alternativas de trabalho pedagógico para os componentes curriculares Ciências (no Ensino Fundamental) e Biologia (no Ensino Médio), mais especificamente, a inserção de recursos midiáticos nas aulas e a realização de práticas experimentais, diante dos recursos disponíveis na realidade do educando.

No tópico seguinte aborda-se o ensino de ciências biológicas através do método tradicional de ensino vislumbrando clarear apontamentos importantes acerca desta metodologia bastante presente nas salas de aula dos dias atuais.

\section{O ENSINO DE CIÊNCIAS BIOLÓGICAS NA PERSPECTIVA DA ESCOLA TRADICIONAL}

A escola tradicional, também chamada de conteudista ou convencional, preponderouse desde o século XIX, até os anos de 1950 e, embora não seja considerada a mais adequada para as práticas atuais, ainda é bastante adotada na realidade. Este método de ensino focaliza o contato com os conhecimentos existentes sobre determinado tema e utiliza como estratégia de ensino aulas as aulas expositivas, que tem como comprovação dessa teoria a unificação do professor e o livro didático como fontes de informação, o estímulo à memorização de conceitos e os experimentos laboratoriais. Desta forma, na escola tradicional o professor transmite seus conhecimentos, os métodos usuais de ensino são aulas expositivas, utiliza-se de técnicas de perguntas e respostas, o aluno é sujeito passivo do processo de ensinoaprendizagem, cabe a este apenas ouvir a explicação e copiar, este deve trabalhar a memorização de conceitos, repetição da informação recebida (ARMSTRONG, 2012). 
Apresentando-se desta maneira, o ensino de ciências e de biologia, não tem trazido resultados satisfatórios, sobretudo a aquisição de conhecimentos por parte dos educandos. Estudos tais como (MORAN, 2006; FISHER, 2014; SILVA, 2015) relatam que uma das possíveis causas apontadas para esse déficit é a maneira de ensinar os conteúdos da disciplina, que muitas vezes é apoiada em concepções equivocadas e não desperta o interesse dos alunos.

Neste sentido, Moran (2006, p. 04), descreve que

Existe uma importante fragilidade no aprendizado, pois faltam estímulos e metodologias adequadas para tornar o aprendizado mais significativo aos educandos, como também uma formação continuada por parte dos professores, pois precisamos repensar o ensino e incentivar propostas mais dinâmicas em sala de aula, inclusive com o uso das tecnologias.

Assim, para o atual ensino de ciências e biologia formatados na maioria das escolas públicas de Sergipe esta abordagem de Moran se encaixa perfeitamente, pois a mesma tem sido muito superficial e o professor, na maioria das vezes, transcreve na lousa listas de exercícios para os alunos estudarem para as provas escritas, cabendo a elas decorar conceitos e regras.

Além disso, deve se considerar que na construção dos conhecimentos de Ciências (ensino fundamental) e Biologia (ensino médio) processados desta maneira não produz uma a aprendizagem significativa e plena, pois a forma como são trabalhadas em sala de aula é de difícil compreensão e visualização por parte dos alunos por abordar determinados fenômenos que na maioria das vezes não há como comprovar empiricamente ou pelo fato dos conteúdos envolverem termos cuja nomenclatura é difícil de se apropriar, conforme explicita Fisher (2014, p. 08):

No Ensino Fundamental há uma mobilidade maior que, por vezes, cai em mal-entendidos e confusões. Não raro ser interpretado como uma listagem de termos a serem memorizados. Já no Ensino Médio o tradicionalismo é muito mais evidente, pois são disciplinas que trazem uma abstração de conceitos distanciados da realidade dos alunos. É relevante, também, a ênfase nos exercícios, na repetição de conceitos ou fórmulas, pois através da memorização se visa disciplinar a mente e formar hábito, o que acaba por adestrar os alunos. 
Assim, fica evidente que o formato tradicional de ensino provoca a falta de interesse e motivação dos alunos haja vista que o conhecimento nesta área requer uma aprendizagem com trabalho intelectual complexo e exigente que vai além da leitura e debate do texto do livro didático ou responder uma lista de exercícios, mas a inserção do educando em outros textos e contextos.

Nesta mesma linha de pensamento sobre o ensino de ciências no contexto tradicional, Silva (2015, p. 65) escreve:

O ensino de ciências no Ensino Fundamental tem se mostrado pouco eficaz no que diz respeito ao desenvolvimento de habilidades que levem os alunos a se questionarem sobre os fenômenos ocorridos na natureza. Já em biologia, no ensino médio, o tradicionalismo é muito mais evidente, devido a abstração de conceitos distanciados da realidade dos alunos.

Assim, a aprendizagem de ciências e de biologia tem se apresentado fragilizada, sem muito significado para o aluno, faltando-Ihes oportunizar a construção de conceitos e habilidades que serão necessários ao entendimento do mundo físico e da natureza e de sua conivência harmônica e sustentável.

Dessa forma, precisa-se criar estratégias para que o conhecimento científico construído deixe de ser "algo inalcançável", desestimulante, vazio, e se torne significativo, sendo conectado com o universo de cada um, estimulando a curiosidade, a investigação, o envolvimento, o gosto pela pesquisa e pela descoberta.

Neste sentido, existem estudos (MORAN, 2006; MOURA, 2011; SILVA, 2015) que sinalizam que as diferentes intervenções de modelos didáticos desenvolvem novos caminhos para o ensino e a aprendizagem de ciências biológicas, visto que estes levam os alunos a atitudes de participação ativa e habilidades de pesquisa-ação, problematizando, realizando pesquisas em diversas fontes e confrontando os resultados, discutindo coletivamente com os seus pares, na busca de respostas as suas indagações, principalmente com a mediação dos recursos tecnológicos, como por exemplo a internet. 
Considerando que existem inúmeros recursos para dar mais significado e dinamismo ao ensino e a aprendizagem de Ciências e Biologia, optou-se por discutir neste trabalho a utilização dos recursos midiáticos, que será a próxima abordagem.

\section{OS RECURSOS TECNOLÓGICOS MIDIÁTICOS ENQUANTO SUPORTE IMPRESCINDÍVEL AO ENSINO DE CIÊNCIAS E BIOLOGIA}

As pessoas na sociedade contemporânea estão diante de uma realidade social informatizada e tecnológica que permite comunicação e interação virtual rápida e transformadora. Neste contexto, encontra-se o aluno, que na maioria das vezes, é proibido do uso destas tecnologias no ambiente escolar, sobretudo na sala de aula, sendo direcionados ao trabalho de "giz e papel", o que pode estar causando a desmotivação para estudar.

Entretanto, se faz necessário interagir com a realidade dos alunos a fim de construir uma interconexão entre professor-aluno e mídia-educação. Assim, é preciso criar alternativas para atrair a atenção dos alunos e conseguir se comunicar de um modo real e produtivo no desenvolvimento da aprendizagem do mesmo, dentro da sala de aula. Para tanto, a escola deverá criar estratégias para valorizar o uso de recursos midiáticos visando proporcionar aos alunos conteúdos com linguagens dinâmicas capazes de incentivá-los a participação cidadã e garantir o desenvolvimento do seu pensamento crítico, quanto as suas ações e a sociedade midiática.

Para Almeida (2015), a imagem produz uma memória ampla da cultura, da ciência e da política. $\mathrm{O}$ visual acaba sendo o real, entendido como verdade que age em várias instâncias da vida social, seja no cotidiano ou em âmbito intelectual ou acadêmico. $E$ corroborando com esta ideia, Diório (2013) explicita que o audiovisual em sua forma tecnológica e informatizada é um meio mais poderoso de difusão e assimilação da realidade social.

Assim, a intensificação do uso dos recursos midiáticos no cotidiano da escola poderá oferecer aos professores, em todas as disciplinas, a possibilidade de incluir em suas aulas estratégias de ensino que privilegie não só os livros didáticos ou textos 
científicos, mas também uma dinâmica que relacione conteúdos produzidos pela mídia de massa aos conteúdos propostos pelo currículo educacional (DÓRIO, 2013).

Desta forma, o educador vai mediatizar dentro sala de aula o uso das tecnologias midiáticas associadas aos recursos educacionais tradicionais, como por exemplo, o livro didático, oferecendo ao aluno possibilidades de interagir, pesquisar, descobrir, refletir e construir seus próprios conceitos, de forma crítica e consciente, haja vista - poder da mídia que é transformador, mas também podendo ser e ao mesmo tempo alienador, em função estar muito presente no cotidiano das pessoas modificando os seus comportamentos, as suas vidas.

Neste sentido, Almeida (2015, p. 13) nos esclarece:

há uma ideologia visual sendo imposta em diversas produções, várias visões históricas sempre se refazendo, produtos populares expondo uma verdade única e um tempo político dominante com diversos poderes que "constrói e reconstrói constantemente mitos e histórias". Há um processo de ver e de identificação que geram as percepções de uma história. Essas imaginações fabricadas pelas lembranças formam uma história que faz sentido ao espectador, representando um momento social e político, e ao mesmo tempo se transformando em uma educação da memória.

Assim, os recursos midiáticos dentro da escola poderão auxiliar professores e alunos no trabalho com informações que estão sendo produzidas velozmente na sociedade contemporânea, na maioria das vezes usadas de má fé, prejudicando pessoas, para que os alunos, a partir das informações dadas, aprendam a lidar com elas, verificar as fontes e a veracidade das mesmas, tronando-se cidadãos críticos.

O uso dos recursos midiáticos pode ser feito desde o ensino fundamental, com filmes, curtas, documentários etc., estimulando o desenvolvimento da oralidade, da expressão, da imaginação, do olhar, da criatividade. Há também um papel importante no uso dessa ferramenta didática, a interdisciplinaridade, o recurso midiático relacionado com a obra escrita, conjugada com o conteúdo dos diversos componentes curriculares. 
No entanto, no trabalho, com os recursos midiáticos em sala de aula, é necessário que o professor seja não apenas um mero espectador, mas sim um sujeito analítico com um olhar crítico para ver e escolher os materiais adequados. Ao submeter a seus alunos um filme, é preciso que os professores o tenham visto primeiro, realizando anotações de pontos importantes, pois um único recurso midiático, assim como este, pode ser objeto de várias interpretações. Atualmente é inegável que há uma produção maior de imagens do que palavras escritas, realizada pelos homens.

Deste modo, não podemos desconsiderar a presença do mundo do entretenimento $\mathrm{e}$ midiático no universo escolar. São variados os personagens que invadem a escola, a família e o indivíduo. Estimular o pensamento crítico do aluno é essencial para que ele seja capaz de tomar boas decisões, evitando que o mesmo possa ser manipulado e dominado pela indústria cultural.

No que diz respeito ao ensino de ciências biológicas, apesar dos grandes avanços da Ciência e da Tecnologia na sociedade contemporânea, observa-se que este permanece ainda, na maioria dos casos, restrito as aulas expositivas com uma pequena participação dos alunos. Deste modo, encontra-se, constantemente, alunos desinteressados nos conteúdos ministrados em sala, com aulas meramente expositivas não condizente com suas necessidades e anseios, se considerar o fato de estarem instantaneamente imersos em novidades e inovação proporcionado pelas novas tecnologias da comunicação e da informação.

$\mathrm{Na}$ sociedade atual, convive-se com o avanço tecnológico e a sua capacidade de proporcionar recursos midiáticos em diversas vertentes que apresenta envolvimento em vários ambientes nas atividades humanas. Sendo assim, as percepções trazidas pelos alunos fazem juízo a este quadro e as mídias (Tv, rádio, celulares, internet, impressos) tem forte influência, contribuindo para o processo de aprendizagem do estudante, unindo a prática em conformidade com o contexto dos conteúdos curriculares propostos em sala de aula. 
Perante isso, a ciência deve possuir funções que vão além dos pareceres tradicionais do currículo escolar. Assim, é preciso que haja uma preparação dos jovens para enfrentar e resolver problemas do cotidiano.

Neste sentido, (KRASILCHIK, 2006, p. 85) enfatiza

os objetivos do ensino de Ciências seriam: aprender conceitos básicos, analisar o processo de pesquisa científica e analisar as implicações sociais da ciência e da tecnologia. As ciências biológicas pode ser uma das disciplinas mais relevantes e merecedoras da atenção dos alunos, ou uma das disciplinas mais insignificantes e pouco atraentes, dependendo do que for ensinado e de como isso for feito.

Entretanto, não existe uma receita pronta de como fazer para que o ensino de ciências seja mais estimulante e atrativo para o aluno, ainda que seja preciso procurar soluções, refletir sobre o assunto e trocar experiências com colegas sobre suas vivencias em sala de aula e também procurar usar adequadamente os recursos midiáticos disponíveis.

Para Silveira (2013), os recursos midiáticos desempenham um papel eficiente no desenvolvimento da aprendizagem através da motivação sobre os alunos referente às novas tecnologias, acredita-se que devido a inclusão de novos meios de comunicação, a atual sociedade tem como característica principal a diversidade de linguagens. A modificação de estratégias de ensino tem como propósito melhorar a qualidade de aprendizagem, partindo da exploração de novos recursos, tais como a aplicação de imagens, movimentos, músicas e artes, criando em um universo imaginário algo a ser transposto na realidade, a fim de ser trabalhado em sala de aula.

Conforme ressaltado nos PCNs (1998, p.44)

o trabalho com recursos midiáticos (Tv, rádio, computador, celular, internet, impressos) podem ser especialmente instigantes e produtivos, tanto pelos resultados da investigação histórica, teórica e prática, quanto pelo próprio percurso dessa investigação. Mas, sobremaneira, pelas significativas contribuições para o processo de ensino e aprendizagem, possibilitando o desenvolvimento nos alunos, de um crescente interesse pela realização de projetos e atividades de investigação e exploração como parte fundamental de sua aprendizagem. 
Da mesma forma, A BNCC, em seus fundamentos pedagógicos destaca o "O compromisso com a educação integral" e orienta que na educação integral o educador intensifique o uso de tecnologia digital para ensinar os diversos componentes curriculares, conforme o seguinte: "[...] atuar com discernimento e responsabilidade nos contextos das culturas digitais, [...]" (BRASIL, 2018, p. 14).

Neste sentido, de forma intensa e continua, percebemos cada vez mais que os recursos tecnológicos e midiáticos fazem a interface de inúmeros usuários em todo o planeta, modificando hábitos de trabalho e de estudo, assim em decorrência desse processo histórico, a escola não deve ficar desatualizada e nem os professores "desconectados". E se tratando da formação do aluno, é de estrema importância que o professor esteja envolvido nas novas tecnologias disponíveis, de modo contínuo, a fim de que possa utilizá-la em sua prática pedagógica.

Assim, as propostas mais adequadas para um ensino de Ciências e Biologia significativo, precisa apresentar um método de aprendizagem que comprometa com as dimensões sociais, políticas e econômicas, fatores estes que Inter textualiza com os campos da ciência, tecnologia e sociedade, capacitando os cidadãos para a tomada de decisões que possam influenciar a vida de todos.

Para D’Ambrósio (2001, p. 06):

é preciso substituir os processos de ensino que priorizam a exposição, que levam a um receber passivo do conteúdo, através de processos que não estimulem os alunos à participação. É preciso que eles deixem de ver a "ciência" como um produto acabado, cuja transmissão de conteúdos é vista como um conjunto estático de conhecimentos e técnicas.

Assim, é preciso que as instituições escolares e os professores envolvidos estejam dispostos a acompanhar as transformações que ocorrem no mundo, a fim de compreendê-las, aceitando os recursos tecnológicos, como um meio para aumentar a eficiência das estratégias na aprendizagem e motivação dos alunos.

Portanto, o educador, e mais especificamente, o professor de ciências, deve buscar constantemente formação continuada para que possa no seu cotidiano de sala de aula 
inserir metodologias participativas, como o trabalho com projetos, como também o emprego de recursos midiáticos dessa forma conectando as suas aulas com as tecnologias e favorecendo o dinamismo, o interesse dos alunos.

Além destes meios midiáticos, vale destacar a realização de aulas experimentais de laboratório e de campo como instrumento de motivação e participação ativa dos educandos e consequente melhoria da aprendizagem no ensino de ciências. Este aspecto será abordado no tópico seguinte.

\section{AS PRÁTICAS EXPERIMENTAIS DE LABORATÓRIO E DE CAMPO}

Apesar de ser consenso para a maioria dos professores de Ciências biológicas o reconhecimento de que a aula prática, experimental, de laboratório e de campo sejam fatores relevantes para a implementação do ensino e a aprendizagem dos conteúdos científicos, de modo didático e estratégico, boa parte destes docentes, não utilizam essas modalidades nas aulas. Na prática aplicam, sobretudo, as aulas expositivas, tendo como material didático, somente o quadro-negro e o giz.

Entretanto, é imprescindível que o educador que trabalha com ciências biológicas se habitue a desenvolver os trabalhos - prático, experimental, laboratorial e de campo com o intuito de ser capaz de realizar uma educação científica de boa qualidade com os seus alunos, auxiliando-os a desenvolverem uma postura crítica e investigativa.

As atividades práticas de laboratório ou de campo devem ser estimuladas, pois as mesmas possibilitam ricas experiências de aprendizagem e cumprem um importante papel pedagógico, desperta a curiosidade, estimula a busca pelo conhecimento, exercita certas habilidades e a prática de valores e atitudes que nem sempre são facilmente exploráveis em sala de aula.

Neste sentido Dourado (2006), assim evidência:

cada uma destas atividades práticas apresenta valor didático particular e inegável ao ensino de Ciências, no sentido de promover o desenvolvimento de competências e habilidades nos alunos nas várias dimensões - atitudinais (trabalhar em grupo, desenvolver o espírito 
científico e a motivação), procedimentais (desenvolver a capacidade de observação, aprender técnicas de campo e laboratorial, desenvolver a capacidade de resolução de problemas) e conceituais (explicar os vários fenômenos, construir conceitos).

Desta forma, o trabalho laboratorial no ensino de ciências biológicas envolve a manipulação de objetos, de ideias e ainda a visualização de fenômenos, tanto no ambiente laboratorial quanto na utilização de materiais laboratoriais em um ambiente diferente, construindo habilidades essenciais para o educando lidar com problemas do seu cotidiano de forma crítica e consciente.

Para Dourado (2006),

O trabalho laboratorial representa as tarefas realizadas com materiais dentro de um laboratório ou mesmo numa sala e o trabalho experimental inclui atividades que envolvem o controle e a manipulação de certas variáveis, ou seja, as experiências que deixam de atender estas condições não podem ser definidas como trabalho experimental

Assim, na realização de atividades experimentais os alunos estabelecem relações reciprocas de cooperação e independência entre si, como também com o professor, efetivando tarefas de ensino-aprendizagem em um ritmo próprio, com elevado domínio e autonomia sobre as mesmas, relatando suas experiências, trocando ideias e produzindo novos conhecimentos.

Entretanto, deve se ter bastante cuidado com as confusões que se faz referendando o que se diz trabalho experimental pois muitos educadores, frequentemente, nas aulas experimentais comanda a prática, através de um manual didático no qual a experiência não possui nenhum caráter investigativo, sendo mera repetição de receitas prontas, sem elucidar nenhuma discussão e consequentemente novas descobertas a respeito do fenômeno investigado.

Neste sentido, Hodson (2000) enfatiza

Simplesmente os estudantes visualizam a experiência comandada pelo professor ou então estes alunos praticam a experiência, porém, ambos já sabem o resultado da prática e assim, apenas comprovam as teorias descritas nas aulas teóricas. Desta forma, é transmitida aos alunos uma 
Ciência pronta, acabada e sem necessidade de questionar a experiência executada.

Ao professor de ciências biológicas convém observar que quando as aulas experimentais são realizadas de forma a repetir receituários de manuais servem apenas para demonstrar o que as teorias já explicam, tornando-se atividades limitadas e não favorecem a construção do conhecimento, recaindo meramente numa exposição de conteúdos e materiais sem muita significação para o educando.

No que se refere ao trabalho de campo, este engloba atividades que são realizadas ao ar livre, onde os fenômenos ocorrem naturalmente, desta forma sendo de fundamental relevância para a motivação do aluno, pois proporcionam o envolvimento deste em situações cotidianas, desenvolvendo assim atitudes positivas em relação às ciências.

Dourado (2006) nos diz que

Além da compreensão conceitual dos conteúdos, o trabalho de campo é capaz de proporcionar aos estudantes a obtenção de conhecimentos procedimentais através do uso da metodologia científica, oportunizando a aquisição de técnicas de campo, atitudes, linguagens, e assim, aprendendo a metodologia.

Portanto, a aula prática, experimental, de laboratório e de campo, se bem conduzida, dentro de uma perspectiva investigativa e de resolução de problemas, proporcionam a criação de situações em que os alunos avaliam os materiais e procedimentos adotados, formulam suas hipóteses, repensam suas ideias a respeito do problema investigado, tomam decisões, enfim, desenvolvem o verdadeiro espírito científico, contribuindo para a formação cidadã e consciente no meio social.

\section{METODOLOGIA DE PESQUISA}

A pesquisa realizada para embasar o estudo é de natureza qualitativa e exploratória, com objetivo de investigar qual é a trajetória do ensino de ciências na escola selecionada como universo de estudo. Para Gil (2008), ao final de uma pesquisa exploratória, o pesquisador conhece mais sobre aquele assunto, e estar apto a 
construir hipóteses. Por ser um tipo de pesquisa muito específica, quase sempre ela assume a forma de um estudo de caso.

Assim, o método adotado para a pesquisa é o estudo de caso. Para Yin (2005), a utilização do estudo de caso é correspondente quando se tem a intensão de investigar o como e o porquê da ocorrência de um conjunto de acontecimentos contemporâneos. O mesmo afirma que o estudo de caso é uma investigação empírica capaz de estudar um fenômeno contemporâneo advindo do contexto da realidade, principalmente quando não há uma definição clara do limite entre o fenômeno e o contexto. Portanto, o uso dessa metodologia como estratégia de pesquisa compreende um procedimento amplo - incluindo uma lógica de organização, das técnicas de coleta de dados e análises especificas dos mesmos.

O Universo pesquisado foi o Colégio Estadual Secretário Francisco Rosa Santos, pertencente a rede pública estadual de ensino, está situada a Avenida Poço do Mero, no 200, Conjunto Bugio, Bairro Assis Chateaubriand, na Cidade de Aracaju, capital do Estado de Sergipe, funcionando nos três turnos de ensino, com modalidades de ensino médio integral e parcial.

Imagem 1 - Fachada do Colégio Francisco Rosa

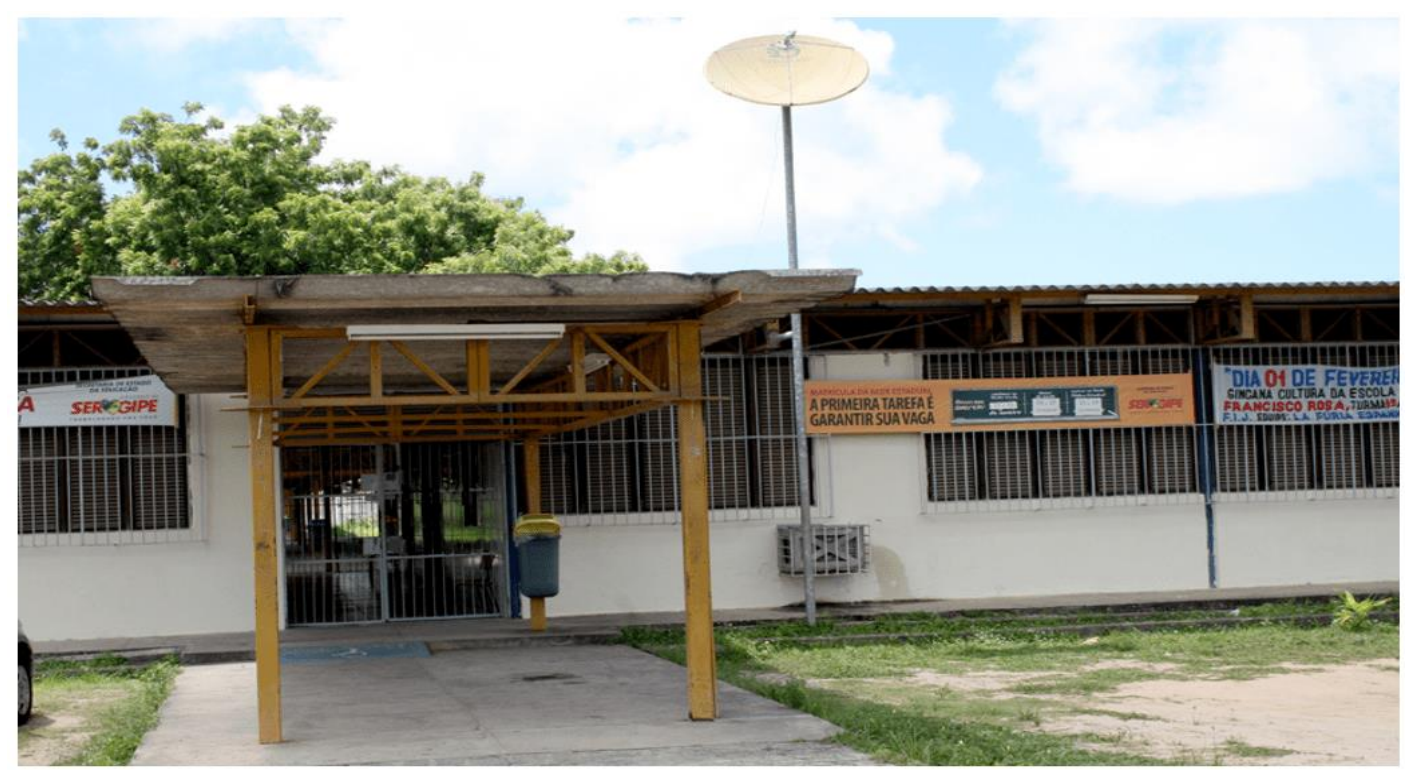

Fonte: Arquivo produzido pelo autor do trabalho, 2020. 
A escola atende a população escolar deste bairro Bugio e circunvizinhas (Olaria, São José, Santos Dumont, Santa Gleide, etc.), localizados na zona leste da capital sergipana. O bairro popularmente conhecido como Bugio foi constituído a partir de um conjunto habitacional do Programa de Habitação Popular do Governo, sendo hoje um dos bairros mais populosos da cidade de Aracaju, sendo sua população constituída principalmente por pessoas provenientes de cidades do interior sergipano e de outras cidades de estados vizinhos que migram para a capital em busca de emprego e melhoria da qualidade de vida (DOCUMENTOS ESCOLAR, 2019).

A unidade de Ensino funciona desde o ano de 1995, ofertando o ensino fundamental e médio, nos turnos matutino, vespertino e noturno. A partir do ano letivo de 2005 , em função do reordenamento do sistema estadual de ensino, a escola passou a ofertar apenas o ensino médio convencional, nos turnos matutino, vespertino e noturno. No ano letivo de 2018, a escola foi incluída pela Secretaria Estadual de Educação no Programa de Ensino Médio Integral nas turmas de primeiros anos.

A Escola possui em sua estrutura física: 01sala de secretaria escolar, 01 sala de Direção, 01 Hall de acesso aos blocos de sala; 03 blocos com um total de 22 salas de aula; 01 sala de biblioteca, 01 sala de professores, 01 laboratório de Ciências, 01 almoxarifado, 04 conjunto de banheiros identificados por gênero, 01 refeitório, 01 laboratório de informática com 20 computadores ligados na internet, 01 cozinha com depósito de armazenar alimentos em anexo, 01 quadra de esportes e área livre, 01 auditório com capacidade para 120 lugares.

Nestes espaços os recursos pedagógicos utilizados pelos professores são: livros didáticos e paradidáticos, Televisão, computadores, quadro branco, ábaco, conjuntos de materiais didáticos industrializados (esqueletos, mapas, material dourado), internet, materiais coletados nas pesquisas, revistas, jornais, Datashow, instrumentos e matérias de laboratório de ciências, além de computadores do laboratório de informática e de materiais do laboratório de Ciências.

Neste universo de pesquisa, algumas questões foram norteadoras: Por que a escola está se tronando desinteressante, desestimulante? Seria o modo como tem sido 
conduzido o ensino que frustra e desmotiva os alunos? Por que as aulas de ciências biológicas não são interessantes? Estas indagações impulsionaram a realização deste trabalho.

Os sujeitos da pesquisa foram os próprios atores escolares que participam do processo de ensino e aprendizagem, em especial, os alunos das turmas do $1^{\circ}$ ano do ensino médio, num total de 70 alunos. Destes, foram selecionados, de forma aleatória, 10 alunos de cada turma, todos provenientes de escolas de ensino fundamental desta região da cidade, sendo: 1A (10 alunos), 1B (10 alunos), 1C (10 alunos), 1D (10 alunos), 1E (10 alunos), 1F (10 alunos) e 1G (10 alunos) matriculados na escola universo de estudo.

Para a realização da coleta de dados e informações a respeito do ensino de ciências e de biologia na escola foi realizada uma abordagem do tipo quanti-qualitativa, pois estudos demonstram que a combinação de métodos quantitativos e qualitativos produz uma triangulação metodológica, visando contribuir com aumento do conhecimento sobre um determinado tema, possibilitando assim o alcance dos objetivos traçados e compreender a realidade estudada (MINAYO, 2016).

O instrumento de pesquisa (questionário) foi formulado com seis perguntas, abrangendo as diversas formas de mediação do conhecimento na disciplina das Ciências Biológicas. As questões abordaram, primeiramente, a afinidade dos estudantes pela disciplina, elencando os conteúdos, abordando a facilidade e a dificuldade em aprendê-los. Foram abordadas, ainda, questões sobre o uso de metodologias diversificadas e qual a importância desses recursos para o ensino de Ciências, além de questionar aos alunos sobre as possíveis contribuições que a disciplina de Ciências possa ter trazido para a vida deles.

Após a construção do instrumento de pesquisa solicitou-se a equipe gestora da escola objeto da pesquisa uma reunião para apresentar o trabalho e solicitar a autorização para realização da pesquisa. Concedida a autorização pelos gestores, iniciou-se a coleta de dados com a aplicação do questionário. Foram selecionados, de forma aleatória, 10 alunos por turma, para participar da pesquisa. Reuniu-se com cada grupo 
de aluno para apresentar 0 trabalho e obter a adesão dos mesmos em participar/contribuir com a pesquisa. A pesquisa teve duração de 05 dias.

Após a coleta dos dados foi realizada a avaliação e o balanceamento dos mesmos. $\mathrm{O}$ estudo de caso se deu por diversos procedimentos de coleta de dados. Portanto, "o processo de análise e interpretação pode, naturalmente, envolver diferentes modelos de análise: de conteúdo, descritiva, inferencial, de discurso, documental”. (YIN, 2005, p.138)

Realizada a pesquisa, processou-se a catalogação e análise dos dados. Diante das respostas obtidas, foi utilizada uma fala de alunos de turmas diferentes, para ilustrar os percentuais, por ter sido representativa da maioria das falas dos alunos da respectiva turma, levando em consideração o que foi mais citado. No que se refere as questões objetivas do questionário, calculou-se a taxa percentual de resultados, já as questões subjetivas não se fizeram análise percentual, entretanto, parte das falas representativas dos alunos de cada série.

Realizada a pesquisa, processou-se a catalogação e análise dos dados. Diante das respostas obtidas, foi utilizada uma fala de alunos de turmas diferentes, para ilustrar os percentuais, por ter sido representativa da maioria das falas dos alunos da respectiva turma, levando em consideração o que foi mais citado.

Os resultados obtidos no estudo de caso foram provenientes da convergência ou da divergência das análises obtidas em diferentes processos. Dessa maneira é que se tornou possível conferir validade ao estudo, evitando que ele fique subordinado à subjetividade do pesquisador. O uso de múltiplas fontes de evidência (YIN, 2005) constitui, portanto, o principal recurso do que se vale o estudo de caso para conferir significância a seus resultados.

\section{RESULTADOS E DISCUSSÃO}

Levando em consideração a pretensão da pesquisa desenvolvida, que foi de investigar a percepção de alunos do $1^{\circ}$ ano do Ensino Médio de uma escola pública 
localizada na cidade Aracaju, capital de Sergipe sobre o ensino de ciências e de biologia neste universo, foram aplicados questionários de pesquisa, do qual sintetizase a seguir os resultados.

Inicialmente foi perguntado aos estudantes: Qual componente curricular que ele mais gosta, destes, 15 indicaram educação física, $12 \mathrm{com}$ português, $9 \mathrm{com}$ Ciências/Biologia, 8 com matemática, 7 com história, 6 com geografia, $6 \mathrm{com}$ sociologia, $4 \mathrm{com}$ inglês, $3 \mathrm{com}$ arte. Assim, indicando nesta ordem, percentuais de $21,43 \%, 17,14 \%, 12,86 \%, 11,43 \%, 10,00 \%, 8,57 \%, 8,57 \%, 5,71 \%$ e $4,29 \%$, respectivamente.

As respostas mais pontuais a esta indagação poderão ser resumidas nas seguintes falas:

"Educação Física, devido a prática de esportes. " (Aluno do $1^{\circ} \mathrm{F}$ );

"Português, porque gosto de leitura de textos, livros. " (Aluno $1^{\circ} \mathrm{A}$ );

"Biologia, entendo mais os seres, o planeta, as coisas, ..." (1 $\left.{ }^{\circ} \mathrm{C}\right)$;

"Matemática, gosto de cálculo, sua exatidão, história. " (Aluno 1 E);

"História, conhece as coisas da sociedade antiga, discute problemas atuais". (Aluna 1G).

Notadamente, as preferências dos alunos por determinados componentes curriculares estão relacionadas as práticas e metodologias efetivadas pelos docentes. O Componente curricular de Educação Física foi aquele mais preferido pelos alunos, em função do tipo de aula que este proporciona: os esportes, que são realizados em ambientes exteriores a sala de aula, em sua grande parte, com maior praticidade e dinamismo. Na sequência, o componente de Língua portuguesa foi o segundo mais preferido devido a dinâmica dos professores desta área que nesta unidade de ensino promovem muitos eventos relacionados a literatura e a leitura. O componente Ciências/biologia foi o terceiro mais preferido pelo grupo de pesquisa, mais em função dos projetos que estão sendo desenvolvidos na escola por professores desta disciplina. 
A seguinte indagação procurou saber quem gostava do componente curricular Ciências/Biologia, tendo a maioria (83\%) respondido que gostavam, mas preferem como está sendo ensinada agora no ensino médio, com a participação em projetos, apesar de provocar mais trabalho. Outros 17\% disseram não gostar do componente curricular pois era "muito enjoado" com palavras difíceis de pronunciar.

Os resultados apontados nas respostas dadas a esta indagação demonstram que a falta de interesse, (17\%) dos discentes pesquisados, pode estar relacionado as dificuldades de compreensão dos conteúdos, talvez pelo conjunto de novas palavras científicas que são desconhecidas destes alunos e estão distantes de seu campo de conhecimento anterior. Além disso, as metodologias de ensino que não propiciam a descoberta através de meios estimulantes e envolventes, muitas vezes reduzidas a lista de exercícios e decoração de textos e conteúdos.

Estes modelos tradicionais de ensinar não favorece o protagonismo do aluno na busca do conhecimento, deixando-o desencorajado, sem atitude, um mero reprodutor dos conteúdos prontos e acabados. Cabe ao professor mudar tal atitude, incentivando os docentes a descoberta do conhecimento através de metodologias ativas e participativas como o uso intensivo de recursos midiáticos, a realização constante de práticas experimentais e pesquisas de campo. $\mathrm{O}$ aluno deverá com tais metodologias se tornar sujeito da ação, planejando, pesquisando, trocando experiências, debatendo e chegando a suas construções e conceitos pertinentes.

Indagou-se, na sequência, como eram trabalhadas as aulas de ciências pelos professores no ensino fundamental, as respostas estão agrupadas nas falas de alguns alunos a seguir.

"O professor manda ler o texto do livro e passa uma lista de perguntas", (aluno 1A).

"O professor explica no quadro o assunto do livro e passa exercícios", (aluno 1F).

"O professor escreve um questionário e manda procurar no livro as respostas", (aluno 1C). 
"O professor explica, mas tem que decorar aqueles conceitos que cai tudinho na prova", (aluno1D).

"Os alunos apresentam na sala o assunto do livro, cada grupo apresenta uma parte", (aluno1 E).

As falas dos alunos indicam que o ensino ainda permanece calçado na metodologia tradicional que tem provocado o desinteresse e apatia dos alunos a escola e o aprendizado dos conteúdos escolares. Para Moran (2006), o processo de aprendizagem apresenta uma importante vulnerabilidade quanto a falta de estímulos, metodologias adequadas e capacitação contínua dos professores para seu aprimoramento, tornando-o mais relevante aos educadores. $O$ mesmo também ressalta que é necessário que haja uma reformulação de ensino com propostas mais dinâmicas em sala de aula, incluindo até mesmo o uso das tecnologias.

Outra pergunta foi relacionada ao que representou maior dificuldade de aprender em ciências. Das respostas apresentadas $75 \%$ apontou a metodologia trabalhada pelo professor (métodos tradicionais) e a forma de avaliação, com muitos questionários para decorar e provas escritas. Outros indicaram o entendimento de algumas palavras e textos. Mais uma vez comprovada a ineficácia do modelo tradicional de ensino e reforçando a necessidade de se introduzir metodologias participativas e novas tecnologias no dia a dia da sala de aula. Neste sentido, o trabalho com didático com uso de recursos midiáticos e as práticas experimentais proporcionarão aos alunos a busca de informação de forma contextualizada, a partir da valorização de seus conhecimentos prévios a respeito do tema tratado, buscando aprofundar as ideias de forma atual e cientifica, através da interface de recursos midiáticos, do trabalho envolvente de todos e da discussão coletiva acerca do problema tratado.

Certamente, se o ambiente de sala de aula for motivador para o aluno na busca de conhecimentos, as dificuldades encontradas se tornarão motivos para a ação destes alunos na busca da superação, pois despertará a curiosidade, emergindo assim novas pesquisas, novas discussões e ampliará o debate enriquecendo cada vez o conhecimento. Neste caso, cabe ao professor intermediar o processo apoiando e incentivando os alunos nas suas descobertas até que tenha sido clareado os pontos 
obscuros e se chegado a um conhecimento significativo. Assim, a construção de um projeto de ensino que priorize o uso dos recursos midiáticos e as aulas experimentais são ferramentas importantes na construção do conhecimento de ciências biológicas.

No que diz respeito as metodologias alternativas que tiveram experiências enumeraram algumas tais como: Práticas experimentais em laboratório, pesquisa de campo, uso de recursos midiáticos (internet, vídeo, documentário). Perguntou-se sobre a aprendizagem em ciências quando se trabalha com práticas experimentais. As respostas dadas estão resumidas nas seguintes falas.

"Com o experimento tem mais trabalho, mas todos se envolvem, dando a sua melhor contribuição, é um trabalho em grupo", (Aluno, 1D).

"No experimento você procura respostas, pesquisa, faz o trabalho, apresenta", (aluna, 1E).

"O experimento ajuda a compreender melhor o que vai estudar, se discute muito o que pesquisa", (aluna, 1A).

"O experimento é feito pelos alunos com a ajuda do professor, mas fica legal, muita coisa a gente ver", (aluna, 1C).

"Todos os alunos são envolvidos e cada um contribui, uns bem mais, outros ficam de carona, mas no final o conteúdo fica entendido por todos", (aluno 1 B).

Diante das respostas dadas pelos alunos é possível afirmar que o trabalho com prática experimental melhora o nível de interesse dos alunos, desperta a sua curiosidade e a sua participação, tornando-os os sujeitos da própria ação, sendo assim, uma metodologia importante para o trabalho na área de ciências biológicas.

Dessa forma, a adoção de recursos metodológicos que incentiva a participação ativa dos alunos durante as aulas pode contribuir, significativamente, para formação de um indivíduo com autonomia e pensamento crítico diante dos saberes científicos essenciais à sua formação e a sua vida em sociedade. (ALVES, 2015).

Além do trabalho didático com experimentos nas aulas de ciências biológicas, outro recurso interessante que foi destacado pelos alunos entrevistados nesta pesquisa foi 
o uso de mídias nas aulas de ciências. Perguntou-se sobre a importância de usar tais recursos nas aulas de ciências biológicas. As respostas dadas estão sintetizadas nas seguintes falas:

"Com estes recursos as aulas ficam mais interessantes, os alunos ficam mais atentos, cada um quer participar", (Alunos do 1A).

"Os recursos trazem imagens, leva você a outros lugares, muito bom para conhecer coisas que estão distantes, ou se já se acabaram”, (aluno, $1 \mathrm{~F})$.

"Eu gosto muito de ver vídeos e analisar seus conteúdos, deixa o assunto mais real para a gente", (aluno 1B).

"É possível interagir, ver outros trabalhos, melhorar o que estamos fazendo", (aluno 1C).

"Com recursos tecnológicos é possível pesquisar em diversos lugares, com mais rapidez, melhorar seus trabalhos", (aluno, 1D).

As respostas dadas constatam a importante dimensão que tais recursos representam na dinâmica das aulas. Os alunos se sentem mais atraídos para realização dos trabalhos escolares, tornando-os mais significativos. A utilização de diferentes recursos no ensino de ciências, sejam eles modelos didáticos ou uso de recursos midiáticos favorece o potencial de desencadear problematizações e estimular a procura por respostas, uma vez que tais atividades oportunizam aos discentes, situações de investigação, gerando um confronto com o desconhecido, com 0 inusitado e inesperado.

Entretanto, mesmo considerando que os recursos como tecnologias midiáticos e os laboratórios experimentais são importantes na perspectiva de melhoria da qualidade do ensino e da aprendizagem de ciências biológicas, deve-se também considerar a relevância em se incentivar a postura docente de tais práticas no seu cotidiano escolar, pois, se estes utilizam apenas as aulas expositivas, certamente os alunos podem não se sentirem motivados a participar e aprender.

Ainda relacionado ao componente curricular ciências procurou-se saber dos alunos sobre a importância dos conteúdos para a sua vida. Estes consideraram de grande 
relevância para a sua vida no planeta e enquanto ser humano, sendo que $73 \%$ achou mais importante os conteúdos relacionados ao meio ambiente e sua preservação, outros $70 \%$ consideraram importante o estudo do corpo humano e sua constituição, $42 \%$ considerou importantes os conteúdos sobre alimentação e saúde, .36\% acharam importantes os estudos relacionados a física e movimentos. De forma geral, consideram a disciplina um conjunto de conhecimentos que contribuem para seu desenvolvimento físico-biológico e social.

No que diz respeito a importância dos conteúdos trabalhados no componente curricular Ciências Biológicas, apesar de certa quantidade de alunos ainda apresentarem dificuldades na apropriação de seus conceitos e postulados, talvez devido a metodologia de ensino que é trabalhada em sala de aula e vivenciada por eles, a maioria considera Ciências/Biologia importante fonte de conhecimentos para a sua vida social e planetária, pois a mesma se torna relevante na formação de condutas, valores e comportamentos diante da sociedade, do meio ambiente e da relação destes com todos os seres vivos.

Portanto, os educadores, e mais especificamente, aqueles que trabalham com componentes curriculares Ciências (Ensino Fundamental) e Biologia (Ensino Médio) deverão fazer reflexão e avaliação sobre as metodologias de ensino que estão sendo empregadas no seu cotidiano escolar, buscando inovar com métodos de ensino e recursos que favoreçam a participação ativa dos educandos, tornando-os sujeitos da pesquisa-ação, contribuindo para a formação de cidadãos críticos, participativos e pensantes.

\section{CONSIDERAÇÕES FINAIS}

A pesquisa realizada foi de natureza qualitativa e exploratória, assumindo o formato de estudo de caso, que proporcionou o estudo de um fenômeno contemporâneo, "O ensino de Ciências Biológicas", dentro de seu contexto da vida real, numa escola da rede pública de ensino, a partir da ótica dos alunos do $1^{\circ}$ ano do ensino médio. 
Para realização da pesquisa buscou-se coletar informações através de questionário semiestruturado que foi aplicado com os educandos selecionados aleatoriamente para amostragem. Além dos questionários coletou-se dados de documentos da escola como planejamento de ensino, diários de classe, cadernos de alunos, visando confrontar as informações. Após a obtenção das informações foi realizada a avaliação, análise e triangulação dos dados.

Os dados da pesquisa revelaram a intensidade da utilização do método tradicional nas salas de aula da escola pública, mais especificamente, nas aulas do componente curricular de ciências biológicas. Que a prática predominante na escola pública de ensino fundamental, das quais os alunos pesquisados eram oriundos, ainda está concentrada em aulas expositivas, através dos textos do livro didático, onde o uso de recursos alternativos como as tecnologias midiáticas, os experimentos laboratoriais e a construção e aplicação de projetos de ensino são praticamente inexistentes, dessa forma, não permitindo que o aluno se torne um sujeito ativo dentro da sala de aula, e consequentemente, fragilizando o seu desenvolvimento.

Apesar de existirem estudos que demonstrem a ineficiência das aulas de ciências no modelo tradicional de ensino no contexto do paradigma atual (sociedade mediatizada por tecnologias da informação e da comunicação) há uma grande resistência para a mudança por parte dos educadores que continuam a utilizá-lo. Quando se prioriza o método tradicional de ensino, há uma negação ao uso de tecnologias por parte dos discentes ao invés de aproveitá-las para dinamizar as aulas e provocar interesses pelas descobertas e pesquisas além de educá-los para o bom uso das tecnologias no cotidiano.

Neste sentido, cabe aos educadores procurar dinamizar suas aulas utilizando métodos participativos como o uso de projetos de ensino que faça uso de recursos tecnológicos midiáticos, a realização de aulas experimentais, de pesquisas de campo, onde o aluno esteja envolvido na construção dos conhecimentos durante o processo de ensinar e aprender, buscando as suas respostas, construindo seus conceitos a partir de suas próprias descobertas e aprofundando seus conhecimentos. 
Para tanto, o trabalho com projetos que utilizem recursos tecnológicos midiáticos e as aulas experimentais se tornam ferramentas imprescindíveis nesta caminhada. Estes dois instrumentais metodológicos apontam nesta pesquisa como caminhos alternativos que poderão melhorar a amplitude dos conhecimentos da área de Ciências Biológicas.

Portanto, sugere-se aos docentes de ciências biológicas a inserção em suas práticas de sala de aula destas metodologias como a elaboração de projetos de ensino a partir de temas relevantes e uso de recursos midiáticos (filmes, documentários, Televisão, Internet, fóruns, entre outros) e a efetivação de práticas experimentais, buscando fortalecer a vinculação do aluno com os conteúdos estudados, favorecer as habilidades de pesquisa, coleta de informações, debates, construção de trabalhos coletivos, cooperação e tornando-os protagonistas de sua própria aprendizagem.

O trabalho alcançou seu objetivo na medida em que permitiu uma aproximação com o contexto escolar e a elaboração de um cenário a respeito das percepções dos alunos em relação ao componente curricular Ciências Biológicas. Dito isso, o presente trabalho teve como finalidade analisar os problemas encontrados e buscar alternativas didático pedagógicas para intervir na realidade e buscar a melhoria da qualidade do ensino nesta área.

Os dados apontam, ainda, que a disciplina de Ciências Biológicas é importante para os alunos, uma vez que apontaram diversos conteúdos e motivos que seriam de grande relevância para as suas vidas físicas, biológicas e sociais.

\section{REFERÊNCIAS}

ALMEIDA. Maik Souza, SANTOS. Felipe Augusto da Silva, DONATO. Elisaf Lino. O ensino da ciência através da física experimental para alunos de $9^{\circ}$ ano das escolas públicas do município de Araruna-PB. In: II Congresso Nacional de Educação, Campina Grande - PB, 2015. Anais II CONEDU - (2015). 
ALVES, Raissa Meirelle Meneses, DE ARAUJO. Maria Simone Medeiros, LUSTOSA, Mariana Silva, GEGLIO, Paulo Cesar. A aula prática no ensino de Biologia: uma estratégia na abordagem do conteúdo de DNA. In: II Congresso Nacional de Educação, Campina Grande - PB, 2015. Anais II CONEDU - (2015).

ARMSTRONG, Diana Lucia de Paula; VARGAS, Liane Maria. Metodologia do ensino de ciências biológicas e da Natureza. Curitiba: Intersaberes, 2012.

BRASIL. Ministério da Educação (MEC). Base nacional comum curricular (BNCC): educação é a base. Brasília: MEC, 2018. Disponível em: <http://basenacionalcomum.mec.gov.br/wp-content/ uploads/2018/12/BNCC_19dez2018_site.pdf>. Acesso em: 06 jan. 2020.

BRASIL. Ministério da Educação. Parâmetros Curriculares Nacionais: Ciências da Natureza, Matemática e suas Tecnologias. Secretaria da Educação Média e Tecnológica - Brasília: MEC; SEMTEC, 1998.

D’AMBRÓSIO, Ubiratã. Educação Matemática: da Teoria à Pratica. Campinas: Papirus, 2001.

DIÓRIO, Ana Paula Inácio. As mídias como ferramenta pedagógica para o Ensino de Ciências: uma experiência na formação de professores de nível médio. p. 55-73. Revista Práxis, Ano V, no 10. Disponível em: < http://web.unifoa.edu.br/praxis/numeros/10/55-73.pdf>. Acesso em: 12 jan. 2020.

DOURADO, Luis. Concepções e práticas dos professores de Ciências Naturais relativas à implementação integrada do trabalho laboratorial e do trabalho de campo. Revista Electrónica de Enseñanza de las Ciencias. v. 5. n. 1. 2006

FISHER, Len. A Ciência no Cotidiano: como aproveitar a ciência nas atividades do dia-a-dia. Tradução, Helena Londres. Rio de Janeiro: Jorge Zahar. 2014.

GIL, Antônio Carlos. Métodos e Técnicas de Pesquisa Social. 6. Ed. São Paulo: Atlas, 2008. 
HODSON, D. The place of practical work in Science Education. En M. Sequeira et al. (Orgs), Trabalho prático e experimental na educação em ciências (pp. 29-42). Braga: Universidade do Minho, 2000.

KRASILCHIK, Myrian. Reformas e realidade o caso do ensino das ciências. São Paulo em Perspectiva, São Paulo, v. 14, n. 1, p. 85-93, 2006.

MINAYO, Maria Cecilia de Souza; ASSIS, Simone Gonçalves de; SOUZA, Edinilsa Ramos de. et al. Métodos, técnicas e relações em triangulação. In: Avaliação por triangulação de métodos: abordagem de programas sociais. Rio de Janeiro, Fiocruz, 2016.

MORAN, José. Manuel. Mediação pedagógica e o uso da tecnologia. In: Novas tecnologias e mediação pedagógica. MORAN, José Manuel, MASETTO, Marcos, BEHRENS, Marilda. 12ª ed. São Paulo: Papirus, 2006.

MOURA, Dácio Guimaraes; BARBOSA, Eduardo Felix Trabalhando com projetos: Planejamento e Gestão de Projetos Educacionais. Editora Vozes, São Paulo: 2011.

SILVA, Edirce Elias da.; FERBONIO, Jaquiele Thayane Gadelha.; MACHADO, Nadja Gomes; SENRA, Ronaldo Eustáquio Feitoza. O Uso de Modelos Didáticos como Instrumento Pedagógico de Aprendizagem em Citologia. Revista de Ciências Exatas e Tecnologia, v.9, n.9, p.65-75, 2015.

SILVEIRA, Jonathan dos Santos da. A tessitura do conhecimento via mídias e redes sociais da internet: notas de uma pesquisa-formação multirreferencial em um curso de especialização. Educ. foco, Juiz de Fora, v. 18, n. 1, p. 43-69, mar. / jun. 2013. Disponível em<disponívelfile://C:/Documents\%20and\%20Settings/Administrador/Desktop/MES TRADO\%2 02011/artigo_sobre_recursos_tecnol\%C3\%93>. Acesso em 06.01.2020.

YIN, Robert K. Estudo de Caso: planejamento e métodos. 3. Ed. Porto Alegre: Bookman, 2005. 
Enviado: Maio, 2020.

Aprovado: Setembro, 2020. 